\title{
Okul Öncesi Öğretmen Adaylarının Sürdürülebilir Çevreye İlişkin Davranış Düzeylerinin İ́celenmesi ${ }^{1}$
}

\section{The Examination of Behavior Levels of Pre-School Teacher Candidates on Sustainable Environment}

\author{
A.Hamit KARADEMIR ${ }^{2} \quad$ Gonca ULUDA $\breve{G}^{3} \quad$ Mehmet Akif CINGi ${ }^{4}$
}

Başvuru Tarihi: 05.12.2016 $\quad$ Yayına Kabul Tarihi: 15.02.2017 $\quad$ DOI: 10.21764/efd.01513

Özet: $\mathrm{Bu}$ araştırmanın amacı, okul öncesi öğretmen adaylarının sürdürülebilir çevreye ilişkin davranış düzeylerini belirlemektir. Nicel paradigmaya sahip olan bu çalışma kesitsel tarama modelindedir. Araştırmanın evrenini Türkiye'deki devlet üniversitelerinin okul öncesi öğretmenliği lisans programlarına devam eden; örneklemi ise, Ağrı İbrahim Çeçen, Anadolu, Ege, Kastamonu ve Muş Alparslan Üniversitelerinde okul öncesi öğretmenliği lisans programlarının 1., 2., 3. ve 4. sinıflarına devam eden ve araştırmaya katılmaya gönüllü olan toplam 1049 öğretmen adayı oluşturmuştur. Araştırmanın verileri 2014 yılının Mayıs ve Haziran aylarında, kişisel bilgi formu ve Demirci Güler ve Afacan (2012) tarafindan öğretim elemanlarına uygulanmak üzere geliştirilen "Sürdürülebilir Çevre Eğitimine Yönelik Davranış Ölçeği” kullanılarak toplanmıştır. Bu ölçek üç alt boyut ve 29 maddeden oluşan beşli likert tipinde bir ölçek olup Cronbach Alpha iç tutarlılık katsayısı 0.94 'tür. Ölçeğin öğretmen adaylarına uygulanabilmesi için okul öncesi eğitimi alan uzmanlarından alınan görüşler doğrultusunda hiçbir maddede değişikliğe gidilmeden 493 adaydan alınan veri üzerinden ölçeğin iç tutarlık güvenirliği yeniden hesaplanmış ve 0.89 olarak belirlenmiştir. 556 adaydan elde edilen veriler, uygun istatistiksel analizlerle çözümlenmiştir. Araştırma sonucunda, öğretmen adaylarının sürdürülebilir çevreye ilişkin davranışlarının cinsiyete ve devam ettikleri üniversiteye göre farklılık gösterdiği; devam ettikleri sınıf düzeyine, sürdürülebilir çevreyle ilgili ders almaya ve bir sivil toplum kuruluşuna üye olma durumuna göre farkl1lık göstermediği belirlenmiştir.

Anahtar Sözcükler: sürdürülebilirlik, sürdürülebilir çevre, okul öncesi ĕgitim, ögretmen adayı
Abstract: The purp.ose of this study is to determine candidates of pre-school teachers' behavior levels towards sustainable environment. The cross-sectional survey was employed in the present study, which was conducted within the quantitative paradigm. The population of the study consists of pre-school teachers attending the undergraduate programs of pre-school education at state universities in Turkey, and the sample of the study is composed of 1,049 pre-service teachers studying at the undergraduate programs of pre-school education at Ağrı İbrahim Çeçen University, Anadolu University, Ege University, Kastamonu University, and Muş Alparslan University in their first, second, third, or fourth years and were voluntary to participate in the study. The research data were collected via personal information form and The Behaviour Scale for Sustainable Environmental Education, developed by Demirci Güler and Afacan (2012) for administration to instructors, in May and June 2014. This scale is a 5-point Likert-type scale consisting of three subdimensions and 29 items. Its Cronbach's alpha coefficient is 0.94. Based on the opinions taken from the domain experts specialized in pre-school education for the administration of the scale to the pre-service teachers, no modification was made in any item, and the internal consistency of the scale was recalculated and found to be 0.89 over the data obtained from 493 pre-service teachers. The data obtained from 556 pre-service teachers were analyzed through appropriate statistical analyses. It was found out that the pre-service teachers' behaviors towards sustainable environment vary by gender and the university attended, but do not differ by grade, status of receiving a course about sustainable development, and status of being a member to a non-governmental organization.

Key Words: sustainability, sustainable environment, preschool education, pre-service teacher

\footnotetext{
${ }^{1}$ Bu çalışmanın ilk hali 2-5 Eylül 2015 tarihlerinde düzenlenen “4. Uluslararası Okul Öncesi Eğitimi Kongresi”nde sözlü bildiri olarak sunulmuştur.

${ }^{2}$ Arş. Gör., Hacettepe Üniversitesi, Eğitim Fakültesi, Türkiye-Ankara, hamittkarademir@gmail.com

${ }^{3}$ Arş. Gör., Hacettepe Üniversitesi, Eğitim Fakültesi, Türkiye-Ankara, gonca.uludag@ hacettepe.edu.tr

${ }^{4}$ Arş. Gör., Kastamonu Üniversitesi, Eğitim Fakültesi, Türkiye-Kastamonu, macingi@ gmail.com
} 


\section{Giriş}

Bireylerin gelişimlerini ve yaşamın tüm alanlarını kapsayan okul öncesi dönemin ilişkili olduğu alanlardan biri de çevredir. Okul öncesi dönemde çocuk, diğer insanlarla, kültürle ve çevreyle ilgili ilişkilerin farkına varmaya ve ilişki ağlarını anlamlandırmaya başlar. Bu dönemde çocukların çevreye olan yoğun merak ve ilgileri yetişkinler ve eğitimciler tarafından desteklenmelidir. Böylece çocukların yaşamın ilk yıllarından itibaren çevreye yönelik olumlu davranışları, beceri, tutum, saygı ve sorumluluk bilinçleri artırılabilir (Gülay ve Önder, 2011). Çünkü okul öncesi dönemde gerek ebeveynlerin, gerek toplumdaki diğer birey ve yetişkinlerin, gerekse eğitimcilerin çevreyle etkileşimi, tutum ve davranışları çocuklar için rol-model niteliğindedir. Dolayısıyla çocukların doğal merak duygularının ve öğrenme isteklerinin yoğun olduğu okul öncesi dönemin uygun şekilde değerlendirilmesi, çocukların yaşadıkları çevreyi tanımaları, çevreye yönelik olumlu tutumlar geliştirmeleri, çevre sorunlarına ilişkin farkındalık kazanmaları ve çevreyi koruma bilinci edinmeleri açısından önem taşımaktadır.

Çevre sorunları çağımızın önemli sorunlarından biri olarak nitelendirilebilir. Öyle ki, doğal kaynakların bilinçsiz ve gereksiz kullanımının, hızla artan dünya nüfusunun, sanayileşmenin, kentleşmenin duyarsızlaşmanın önemli çevre sorunlarına yol açtığı; bu nedenle gerekli önlemlerin alınması ve konu ile ilgili çalışmaların yapılması gereği kaçınılmaz bir gerçektir. Çevrenin korunmasına yönelik farkındalık geliştirmek ve sorunlarla mücadele etmek tüm insanlığın sorumluluğundadır. Bu noktada "sürdürülebilirlik" kavramının bilinmesi ve benimsenmesi büyük önem taşımaktadır.

İlk kez 1970’li yıllarda kullanılmasına rağmen, 1987 yılında Birleşmiş Milletlerin sponsorluğundaki Dünya Çevre ve Kalkınma Komisyonu'nun (WCED) yayınladığı “Ortak Geleceğimiz” raporunda sürdürülebilirlik; “günümüzün gereksinimlerinin, gelecek nesillerin kendi gereksinimlerini karşılayabilme olanaklarından ödün vermeden karşılanabilmesi” şeklinde tanımlanmıştır (Önder ve Özkan, 2013). Buna göre sürdürülebilirlik, günümüz ihtiyaçlarını karşılamak için kaynakların gerektiği kadarının kullanılmasını, bu kullanım yapılırken sonraki nesillerin ihtiyaçlarının da düşünülmesi gerektiğine odaklanan bir kavramdır. Kaynakların bilinçli tüketiminin yanı sıra, kullanılan kaynă̆ın yerine konulması için verilecek çaba da sürdürülebilirliğin bir parçasıdır. Önder ve Özkan (2013)'e göre sürdürülebilirliğin esası; doğal kaynakların verimli kullanılmasına, atıkların azaltılmasına, kaynakların geri dönüşümünün sağlanmasına, gelecek nesillerin ihtiyaçlarına cevap şekilde çevrenin sürekli korunmasına dayanmaktadır.

Sürdürülebilir kalkınma ise, herkesin temel gereksinimlerini karşılayabilme ve kaynakların kullanımı, yatırımların yönlendirilmesi, teknolojinin yönünün belirlenmesi ve kurumsal değişiklikler yaşanırken insanlığın beklentilerinin dikkate alınmasını amaçlayan bir değişim sürecidir (Karabulut, 2004, s.72). Sürdürülebilir kalkınmanın sosyal, ekonomik ve çevresel olmak üzere birbiri ile ilişkili üç boyutu bulunmaktadır (UNESCO, 2005). Sürdürülebilir kalkınmanın sosyal boyutu karar verme sürecinde demokratik katılımın-eşitliğin ve yüksek istihdamın olduğu bir toplum yapısını tanımlamakta, ekonomik boyutu güçlü ve sağlam bir ekonomik büyüme, düşük ve istikrarlı enflasyon, büyük bir yatırım, yenilik 
kapasitesi ve finansal istikrar getirmektedir. Çevresel boyutu ise biyolojik ve fiziksel sistemlerin bütünlüğünün ve verimliliğinin devam ettirilmesi ile sağlıklı bir çevrenin oluşturulup korunmasını gerektirmektedir (OECD, 2001; akt. Uysal, 2013). Günümüzde sürdürülebilir kalkınma düşüncesinin giderek sürdürülebilir çevre eğitimine doğru ivme kazandığı görülmektedir (Tanrıverdi, 2009).

Çevrenin sürdürülebilirliği, doğal kaynakların kendini yenileme kapasitesinden daha hızlı bir şekilde tüketilmemesini, çevresel açıdan zararlı faaliyetlerin kontrol altına alınması gerektiğini ifade etmekte (Engin, 2010), bitki ve hayvan türlerinin korunmasını, hava, su ve diğer doğal elemanların kalitesi üzerindeki kötü etkilerin en aza indirilerek ekosistemin devamlılığını sağlamayı gerektirmektedir (Keleş, 2007). Çevrenin sürdürülebilir olmasının sağlanması için bireylerin okul öncesi dönemden itibaren çevreyi koruma bilinciyle yetişen tüketiciler olması gereklidir. Nickell (1976) çevre bilinci olan tüketicinin, çevre kirliliğine karşı kendi etkinliğini kavradığını, kaynak kullanımında gelecek nesiller ve tüm insanlık için duyarlı bir tutum içinde olduğunu ifade etmiş, bu tüketicilerin çevredeki kaynakların varlığını, kullanım maliyetini, kullanımın çevreye ve kendilerine olan etki boyutlarını değerlendirebileceklerini belirtmiştir (Bener ve Babaoğul, 2008).

Çevre dostu olmak, sürdürülebilirliğe katkı sağlamak, dünyayı sonraki nesiller için yaşanılabilir şekilde kullanmak, çevreyi önemsemek her bireyin yerine getirmesi gereken bir sorumluluk olarak dikkat çekmektedir. $\mathrm{Bu}$ sorumluluk bilincini gelecek nesillere aktarmakta etkin rol oynayanlardan biri de eğitimcilerdir. Okul öncesi dönemden itibaren çocukların çevreye karşı duyarlı olmaları, çevrenin sürdürülebilirliğine ilişkin farkındalık kazanmaları için, eğitimcinin çevreye yönelik tutumunun olumlu olması ve bu tutuma uygun davranışlar sergilemesi çocuklar için model teşkil etmektedir. Erten (2005)'e göre çevre problemleri bireysel davranışların değişmesiyle, davranışların değişmesi ise tutum, bilgi ve değer yargılarının değişmesi ile mümkündür. Dolayısıyla bugünün genç nesli olan ve okul öncesi dönemdeki çocukları eğitmek üzere yetiştirilen okul öncesi öğretmen adaylarının sürdürülebilir çevreye ilişkin davranış ve tutumları hakkında bilgi edinilmesi, onlara verilecek mesleki ve genel kültür eğitimlerinin kalitesinin artırılması ve kişisel gelişimlerine destek olunması açısından önem taşımaktadır. Bu noktadan hareketle araştırmada, okul öncesi öğretmen adaylarının sürdürülebilir çevreye ilişkin davranış düzeylerini ortaya koymak amaçlanmıştır.

\section{Yöntem}

\section{Araştırmanın Yöntemi}

Veri bağlamında nicel paradigmaya sahip olan bu çalışma, tarama araştırma çeşitlerinden kesitsel tarama modelindedir. Tarama araştırmaları bir konu ya da olaya ilişkin katılımcıların görüşlerinin, tutum, ilgi, kaygı gibi özelliklerinin belirlendiği çalışmalardır (Büyüköztürk, Çakmak, Akgün, Karadeniz ve Demirel, 2011). Başka bir ifadeyle tarama modelleri geçmişte olan ya da hala var olan bir durumu var olduğu biçimiyle betimlemeyi amaçlayan araştırma yaklaşımlarıdır. Araştırmaya konu olan olay, birey ya da nesneyi herhangi bir biçimde değiştirme ve etkileme çabası gösterilmez. Önemli olan, onu uygun bir biçimde gözleyip belirleyebilmektir (Karasar, 2005, s. 77). 


\section{Evren ve Örneklem}

Araştırmanın evrenini Türkiye'deki devlet üniversitelerinin okul öncesi öğretmenliği lisans programlarına devam eden öğretmen adayları oluşturmaktadır. Araştırmanın örneklemi ise, zamandan ve maddi maliyetten tasarruf sağlamak için amaçlı örneklem yollarından uygun (erişilebilir) örneklem temel alınarak belirlenmiştir. Buna göre araştırmanın örneklemini Ağrı İbrahim Çeçen Üniversitesi, Anadolu Üniversitesi, Ege Üniversitesi, Kastamonu Üniversitesi ve Muş Alparslan Üniversitesi'nde okul öncesi öğretmenliği lisans programlarının 1., 2., 3. ve 4. sınıflarına devam eden toplam 1049 öğrenci oluşturmuştur.

\section{Verilerin Toplanmas1}

Araştırmanın verileri, 2014 yılının Mayıs ve Haziran aylarında, araştırmacılar tarafından oluşturulan, öğretmen adayının cinsiyetine, eğitime devam ettiği üniversiteye, kaçıncı sınıfa devam ettiğine, sürdürülebilir çevre eğitimi aldığı ders türüne ve çevre ile ilgili bir sivil toplum kuruluşuna üye olup olmamasına ilişkin toplam 5 sorudan oluşan kişisel bilgi formu ile Demirci Güler ve Afacan (2012) tarafından geliştirilmiş olan "Sürdürülebilir Çevre Eğitimine Yönelik Davranış Ölçeği” kullanılarak toplanmıştır. Bu ölçek, öğretim elemanlarının sürdürülebilir çevreye ilişkin davranış düzeylerini belirlemek üzere geliştirilmiştir. "Enerjiyi Tasarruflu Kullanma” , "Çevre Hakkında Yayınların Takibi ve Çevreye Zarar Veren İnsanlara Karşı Tepki” ve “Çevre Dostu ve Geri Dönüşümlü Ürünleri Kullanma” olmak üzere üç alt boyuttan ve toplam 29 maddeden oluşan beşli likert tipindeki bu ölçeğin, tamamı için hesaplanan açıklanan varyans \%55.251'tür. Ölçeğin 15 maddesi bulunan “Enerjiyi Tasarruflu Kullanma” alt boyutu için açıklanan varyans \%24.336 ve faktör yükleri 0.474 ile 0.792 arasında değişmekte olup, Cronbach Alpha katsayısı 0.919'dir. 8 maddesi bulunan "Çevre Hakkında Yayınların Takibi ve Çevreye Zarar Veren İnsanlara Karşı Tepki” alt boyutu için açıklanan varyans \%19.263 ve faktör yükleri 0.627 ile 0.782 arasında değişmekte olup, Cronbach Alpha katsayısı 0.898'dir. 6 maddesi bulunan “Çevre Dostu ve Geri Dönüşümlü Ürünleri Kullanma" alt boyutu için açıklanan varyans \%11.651 ve faktör yükleri 0.436 ile 0.724 arasında değişmek olup, Cronbach Alpha katsayısı 0.793 olarak hesaplanmıştır. Ölçeğin tamamı için hesaplanan Cronbach Alpha iç tutarlılık katsayısı ise 0.944'tir (Demirci Güler ve Afacan, 2012).

Öğretim elemanlarının sürdürülebilir çevreye ilişkin davranış düzeylerini belirlemek üzere geliştirilen bu ölçek, öğretmen adaylarına uygulanmadan önce okul öncesi eğitim alan uzmanlarının görüşüne sunulmuştur. Uzmanlardan alınan dönütler doğrultusunda ölçeğin hiçbir maddesinde değişiklik yapmaya gerek duyulmadığı belirlenmiş, ölçeğin öğretmen adaylarına uygulamaya uygun olduğu bilgisi edinilmiştir. Örneklem grubunda yer alan 1049 öğretmen adayından elde edilen veriler, tabakalı örnekleme yöntemine göre seçkisiz olarak ikiye ayrılmış ve 493 adaydan alınan veri üzerinde ölçeğin iç tutarlık güvenirliği hesaplanmıştır. Ölçeğin tamamı için hesaplanan Cronbach Alpha iç tutarlılık katsayısı 0.89 olarak belirlenmiştir. Ölçeğin her bir alt boyut için hesaplanan iç tutarlılık katsayıları da Tablo 1'de sunulmuştur. 
Tablo 1. Alt Boyutlar İçin Hesaplanan Cronbach Alpha Katsayıları

\section{Boyutlar}

Enerjiyi Tasarruflu Kullanma

Çevre Hakkında Yayınların Takibi ve Çevreye Zarar Veren İnsanlara Karşı Tepki

Çevre Dostu ve Geri Dönüşümlü Ürünleri Kullanma
Cronbach Alpha

katsayıları

0.80

0.83

0.82

Tablo 1'de görüldüğü üzere, Cronbach Alpha katsayıları 0.80 ile 0.83 arasındadır. Elde edilen bu sonuçlar hem ölçeğin tamamı hem de ölçeğin alt boyutları için hesaplanan iç tutarlılık katsayılarının oldukça yüksek olduğunu ve dolayısıyla yüksek güvenirlik düzeyine sahip olduğunu göstermektedir (Özdamar, 2011).

$\mathrm{Bu}$ araştırma kapsamında ölçeğin yapı geçerliği kanıtı olarak 493 kişiden oluşan veri üzerinde Doğrulayıcı Faktör Analizi (DFA) yapılmıştır. Bu analiz için SPSS 20 ile LISREL 8.71 programları kullanılmış ve DFA'nın varsayımı gereği kayıp değer, uçdeğer, çok değişkenli normallik, doğrusallık ve çoklu bağlantılılık incelenmiştir. Yapılan incelemeler sonucunda 27 kişinin normal dağılımı bozduğu tespit edilmiş ve 466 kişi ile “Sürdürülebilir Çevre Eğitimine Yönelik Davranış Ölçeği”nin geçerlik kanıtı ortaya konulmuştur. KaiserMeyer-Olkin Measure of Sampling Adequancy (KMO) ve Bartlett's Test of Sphericity değerleri, verinin DFA için son derece uygun olduğunu göstermektedir $(\mathrm{KMO}=0,87 ; \mathrm{p}<.01)$. Tüm LISREL analizlerinde en çok olabilirlik kestirimleri (Maximum likelihood) tekniği kullanılmıştır. Bu araştırmada öngörülen modelin veri tabanına uygunluğunu değerlendirmek için ki-kare, GFI (Goodness-of-fit index), AGFI (Adjusted goodness-of-fit index), CFI (Comparative fit index), NFI (Normed fit index), NNFI (Non-normed fit index), SRMR (Standardized root mean square residuals) ve RMSEA (Root mean square error of approximation) gibi araştırmalarda çok sık kullanılan çeşitli model uyum indeksleri kullanılmıştır.

Tablo 2. Sürdürülebilir Çevre Eğitimine Yönelik Davranış Ölçeği'nin DFA Sonucundaki Uyum İndeksleri

\begin{tabular}{cccccccc}
\hline$\chi^{2} / \mathrm{sd}$ & RMSEA & SRMR & AGFI & GFI & CFI & NFI & NNFI \\
\hline 3.65 & 0.048 & 0.047 & 0.80 & 0.83 & 0.92 & 0.89 & 0.91 \\
\hline
\end{tabular}

Analiz sonuçlarına göre model uyum indeksleri değerlendirildiğinde ki-kare $(1117.81 ; p=0,00)$ değerinin anlamlı olduğu görülmektedir. Ki-kare değeri örneklem büyüklüğüne oldukça duyarlı olduğu için örneklem büyüklüğü arttıkça ki-kare değerinin anlamlı çıkma olasılı̆̆ı artmaktadır (Kline, 2005; Şimşek, 2007). Kikare analizinde serbestlik derecesinin de önemli bir ölçüt olduğu ifade edilmekte ve uyum iyiliğine ilişkin yorum yapmak için ki-kare/sd oranı kullanılmaktadır (Ayyıldız, Cengiz ve Ustasüleyman, 2006; Şimşek, 2007). Bu oran için kabul edilebilir sınırlar tam olarak belirlenmemiş olsa da, 2 ile 5 arasında olması kabul edilebilir uyum, 2'den küçük olması ise iyi uyum göstergesi olarak ifade edilmektedir (Kline, 2005; Tabachnick ve Fidell, 2006). Bu araştırmada ki-kare/sd değeri 3.65 bulunmakla birlikte kabul edilebilir uyum indeksine sahip olduğu görülmektedir. Jöreskog ve Sorbom (1993), hesaplanan GFI ve AGFI 
değerlerinin 0.85 'ten yüksek olması durumunda kabul edilebilir uyum olduğunu belirtmektedir. Bu çalışmada kurulan modelin GFI uyum indeks değerinin 0.83 ve AGFI uyum indeks değerinin 0.80 olarak hesaplanması bu değerlerin model veri uyumu için kabul edilebilir olmadığını göstermektedir. Literatür incelendiğinde GFI ve AGFI indekslerinin 0 ile 1 arasında değiştiği ve örneklem büyüklüğüne duyarlı olduğu için büyük örneklemlerde daha uygun değerler verdiği görülmektedir (Tabachnick ve Fidell, 2006). Bu araştırma kapsamında örneklem sayısının görece küçük olması GFI ve AGFI değerlerinin kabul edilebilir ölçüt değerlerinin biraz altında olmasına sebep olduğu düşünülmektedir. Bu bağlamda elde edilen GFI ve AGFI uyum indeklerinin de yorumlanması için yeterli düzeyde olduğu sonucuna ulaşılabilmektedir. SRMR ve RMSEA değerlerinin 0.05 'ten düşük olması iyi model veri uyumunu göstermektedir (Jöreskog ve Sorbom, 1993). Bu araştırma kapsamında RMSEA $(0,048)$ ve SRMR $(0,047)$ kabul edilebilir uyum göstermektedir. Ayrıca bulunan NFI (0.89), NNFI (0.91) ve CFI (0.92) değerleri kabul edilebilir düzeyde model-veri uyumu olduğunu ortaya koymaktadır. Sonuç olarak model veri uyumuna ilişkin değerlerin tamamı dikkate alındığında bulunan indekslerin kurulan modelin değişkenleri arasındaki ilişkileri kabul edilebilir düzeyde açıkladığı ve kurulan modelin veri uyumunun kabul edilebilir olduğu görülmektedir. Başka bir ifade ile elde edilen bu değerler 29 maddelik 3 boyutlu modelin veri ile uyum gösterdiğini ve modelin istatistiksel açıdan uygun olduğunu işaret etmektedir.

Verilerin Analizi ve Yorumlanmas1

1049 öğretmen adayından elde edilen verilerden 493'ünün ölçeğin iç tutarlılık güvenirliğini hesaplamada kullanılmış olması sebebiyle, geriye kalan 556 veri analiz sürecine dahil edilmiştir. Öğretmen adayların ortalama puanları arasında anlamlı farklılıkların araştırıldığı değişkenlere yönelik normallik testi “Kolmogorov-Smirnov" yapılmış; merkezi eğilim ve dağılım ölçüleri incelenmiştir. Yapılan incelemeler sonucunda öğretmen adaylarının sürdürülebilir çevreye ilişkin puanlarının normal dağıldığı fakat cinsiyet ve sürdürülebilirlikle ilgili alınan ders türü değişkenlerinin kategorileri düzeylerinde normal dağılımın olmadığı belirlenmiştir. Bu bağlamda araştırma verileri Mann-Whitney U testi, One Way Anova testi, Ki-kare ve Bağımsız örneklemler için t testi analizi kullanılarak çözümlenmiştir.

\section{Bulgular ve Tartışma}

Öğretmen adaylarının sürdürülebilir çevreye ilişkin davranış düzey puanları ile cinsiyete, eğitime devam edilen üniversiteye, sınıf düzeyine, sürdürülebilir çevre eğitimi aldığı ders türüne ve çevre ile ilgili bir sivil toplum kuruluşuna üye olup olmamasına ilişkin elde edilen bulgular tablolar halinde sunulmuştur.

Öğretmen Adaylarının Sürdürülebilir Çevreye İlişkin Davranış Düzey Puanları İle Cinsiyete İlişkin Bulgular

Öğretmen adaylarının "Sürdürülebilir Çevre Eğitimine Yönelik Davranış Ölçeği”nden elde ettikleri puan ortalamalarının cinsiyete göre anlamlı bir biçimde farklılaşıp farklılaşmadığını belirlemek amacıyla MannWhitney U testi uygulanmıştır. 
Tablo 3. Sürdürülebilir Çevreye İlişkin Davranış Düzey Puanlarının Cinsiyete Göre Mann- Whitney U-Testi Sonuçları

\begin{tabular}{lccccc}
\hline Cinsiyet & $\mathbf{N}$ & Sira Ortalaması & Sira Toplamı & U & p \\
\hline Kadın & 493 & 288.39 & 142463.00 & 10924.00 & $.000^{*}$ \\
Erkek & 63 & 205.40 & 12940.00 & - & - \\
\hline
\end{tabular}

Tablo 3'e göre, kadın öğretmen adaylarının sürdürülebilir çevreye ilişkin puan ortalamalarının erkek adaylara kıyasla daha yüksek olduğu ve grupların sürdürülebilir çevreye ilişkin davranış puanları arasındaki farkın istatistiksel olarak anlamlı olduğu görülmektedir. Test sonucu hesaplanan etki büyüklüğü değeri ( $(\mathrm{r}=-$ 0,16) cinsiyetin adayların sürdürülebilir çevreye ilişkin puanları üzerinde düşük düzeyde etkiye sahip olduğunu göstermektedir (Field, 2009; Green ve Salkind, 2008).

Okul öncesi eğitimi lisans programlarını tercih eden adayların ve programa devam eden öğrencilerin çoğunlukla kadınlardan oluşmasının, araştırmanın bu bulgusu üzerinde etkili olduğunu düşündürmektedir. Elde edilen bu bulgu, cinsiyetin çevreye duyarlılığa etkisini inceleyen çeşitli çalışmaların (Aksoy ve Karatekin, 2011; Atasoy ve Ertürk, 2008; Çabuk ve Karacaoğlu, 2003; Eagles ve Demare, 1999; Erol ve Gezer, 2013; Gürbüz ve Çakmak, 2012; Timur, Yılmaz ve Timur, 2013) sonuçlarıyla da paralellik göstermektedir. Aydın ve Ünaldı (2013) coğrafya öğretmenliği programında öğrenim gören öğrencilerin sürdürülebilir çevreye ilişkin tutumlarını değerlendirdikleri çalışmalarında da kız öğrencilerin sürdürülebilir çevreye ilişkin tutum puanlarının erkek öğrencilerin puanlarına göre daha yüksek olduğu sonucuna ulaşmışlardır. Tikka, Kuitunen ve Tynys (2000) kadınların erkeklere göre çevreye karşı daha duyarlı olduklarını belirtmiş; Sadık ve Çakan (2010), kadın öğrencilerin erkek öğrencilere göre sürdürülebilir çevreye yönelik duyarlılıklarının daha yüksek olmasında hemen hemen tüm toplumlarda kadın rolüne yüklenen ideal imajın etkili olabileceğini ifade etmişlerdir.

Öğretmen Adaylarının Sürdürülebilir Çevreye Yönelik Davranış Düzey Puanları İle Devam Ettikleri Üniversiteye İlişkin Bulgular

Öğretmen adaylarının puan ortalamalarının devam ettikleri üniversiteye göre anlamlı bir biçimde farklılaşıp farklılaşmadığını belirlemek amacıyla Anova testi uygulanmıştır.

Tablo 4. Sürdürülebilir Çevreye İlişkin Davranış Düzey Puanların Devam Edilen Üniversiteye Göre Anova Sonuçları

\begin{tabular}{lllllll}
\hline Varyansın Kaynağı & $\begin{array}{l}\text { Kareler } \\
\text { Toplamı }\end{array}$ & $\mathbf{n}$ & Kareler & $\mathbf{F}$ & p \\
Ortalaması & & Anlamlı Fark \\
\hline Gruplararası & 54489.779 & 4 & 13622.445 & 99.519 & $.000^{*}$ & Ege-Ağrı, \\
& & & & & & Ege-Kastamonu \\
Gruplariçi & 75559.402 & 552 & 136.883 & & Ege-Anadolu \\
\hline
\end{tabular}




\begin{tabular}{|c|c|c|}
\hline Toplam & 130049.181 & Ege-Muş \\
\hline
\end{tabular}

Tablo 4'teki analiz sonuçları incelendiğinde, öğretmen adaylarının sürdürülebilir çevre eğitimine yönelik davranış puanları ile eğitim gördükleri üniversitelerinin en az ikisi arasında istatistiksel olarak manidar farkın olduğunu göstermektedir $[\mathrm{F}(4,556)=99,519, \mathrm{p}<.05]$. Başka bir ifade ile öğretmen adaylarının sürdürülebilir çevre eğitimi puanlarının eğitim gördükleri üniversitelere göre farklılaştığı bulunmuştur. Hangi üniversitelerde eğitim görmekte olan öğretmen adaylarının sürdürülebilir çevre eğitimine yönelik davranış puanları ortalaması arasındaki farkın anlamlı olduğunu bulmak amacı ile yapılan Dunnett $\mathrm{C}$ testi sonuçlarına göre, Ege Üniversitesi’nde öğrenim gören öğrencilerin sürdürülebilir çevre eğitimine yönelik puan ortalamalarının Ağrı İbrahim Çeçen, Anadolu, Kastamonu ve Muş Alparslan Üniversiteleri’nde öğrenim görmekte olan öğrencilerin puan ortalamalarından manidar bir şekilde yüksek olduğu sonucuna ulaşılmıştır. Test sonucu hesaplanan etki büyüklüğü değeri $\left(n^{2}=0,42\right)$ öğretmen adaylarının sürdürülebilir çevre eğitimi davranış puanlarının eğitim gördükleri üniversiteler üzerinde yüksek düzey etkiye sahip olduğunu göstermiştir (Green ve Salkind, 2008). Örneklemde yer alan üniversitelerin 2011-2014 yılları okul öncesi eğitimi lisans yerleştirme puanları incelediğinde Ege Üniversitesi’nin taban puanlarının diğer üniversitelerin taban puanlarından daha yüksek olduğu görülmüştür (www.ösym.gov.tr). Bu sonuç, akademik başarı ile sürdürülebilir çevreye ilişkin davranış düzey puanları arasında doğrusal bir ilişki olduğunu düşündürmektedir.

Öğretmen Adaylarının Sürdürülebilir Çevreye İlişkin Davranış Düzey Puanları İle Devam Ettikleri Sınıf Düzeyine İlişkin Bulgular

Öğretmen adaylarının puan ortalamalarının devam ettikleri sınıf düzeyine göre anlamlı bir biçimde farklılaşıp farklılaşmadığını belirlemek amacıyla Anova testi uygulanmıştır.

Tablo 5. Sürdürülebilir Çevreye İlişkin Davranış Düzey Puanlarının Betimsel İstatistikleri

\begin{tabular}{lccc}
\hline Sınıf düzeyi & $\mathbf{N}$ & $\bar{x}$ & SS \\
\hline Birinci sınıf & 156 & 104.55 & 13.02 \\
İkinci sınıf & 182 & 103.46 & 16.37 \\
Üçüncü sınıf & 116 & 105.59 & 15.77 \\
Dördüncü sınıf & 102 & 106.20 & 15.99 \\
\hline
\end{tabular}

Tablo 6. Sürdürülebilir Çevreye İlişkin Davranış Düzey Puanlarının Devam Ettikleri Sınıf Düzeyine Göre Anova Testi Sonuçları

\begin{tabular}{lccccc}
\hline Varyans Kaynağı & Kareler Toplamı & sd & Kareler Ortalaması & F & p \\
\hline Gruplararası & 610.768 & 3 & 203.589 & 0.870 & .457 \\
Gruplariçi & 129438.413 & 553 & 136.883 & & \\
Toplam & 130049.181 & 556 & & \\
*p<.05 & & & &
\end{tabular}


Tablo 5 incelendiğinde sınıf düzeyinde öğretmen adayı sayılarının farklılık gösterdiği ancak adayların puan ortalamalarının birbirine çok yakın olduğu görülmektedir. Tablo 6 incelendiğinde ise öğretmen adaylarının sürdürülebilir çevre eğitimine yönelik davranış puanları ile devam ettikleri sınıf düzeyi arasında istatistiksel olarak anlamlı farkın olmadığ1 görülmektedir $[\mathrm{F}(3,556)=0,870, \mathrm{p}>.05]$. Başka bir ifadeyle öğretmen adaylarının sürdürülebilir çevre eğitimine yönelik davranış puanları devam ettikleri sınıf düzeyine göre farklılaşmamaktadır. $\mathrm{Bu}$ bulgu, öğretmen adaylarının üniversitedeki eğitim yaşantıları ile sosyal yaşamlarının sürdürülebilir çevreye yönelik farkındalık kazanmaları noktasında etkili olmadığını düşündürmektedir. Bu bulgunun aksine, Çabuk ve Karacaoğlu (2003) tarafindan üniversite öğrencileriyle yapılan çalışmada ise son sınıf öğrencilerinin alt sınıftaki öğrencilere göre daha fazla çevre duyarlılığına sahip olduklarını belirlemişlerdir. Gürbüz, Kışoğlu ve Erkol (2007) tarafından biyoloji öğretmen adaylarıyla yapılan çalışma sonucunda çevre eğitimi dersi alan beşinci sınıf öğrencileriyle çevre eğitimi dersi alamayan birinci sınıf öğrencilerinin çevreye yönelik tutumları arasında istatistiksel olarak anlamlı bir farkın bulunmadığı ortaya konulmuştur.

Öğretmen Adaylarının Sürdürülebilir Çevreye İlişkin Davranış Düzey Puanları İle Sürdürülebilir Çevre Eğitimini Aldıkları Ders Türüne İlişkin Bulgular

Öğretmen adaylarından 136'sı sürdürülebilir çevre eğitimi ile ilgili ders aldıklarını ifade etmişlerdir. Buna göre, öğretmen adaylarının “Sürdürülebilir Çevre Eğitimine Yönelik Davranış Ölçeği”nden elde ettikleri puan ortalamalarının sürdürülebilir çevre eğitimi aldıkları ders türüne göre anlamlı bir biçimde farklılaşıp farklılaşmadığını belirlemek amacıyla Bağımsız Örneklemler için T testi uygulanmıştır.

Tablo 7. Sürdürülebilir Çevreye İlişkin Davranış Düzey Puanlarının Sürdürülebilir Çevre Eğitiminin Alındı̆̆ı Ders Türüne Göre T-Testi Sonuçları

\begin{tabular}{lccccccc}
\hline Ders Türü & $\mathbf{n}$ & $\bar{x}$ & $\mathbf{S}$ & $\mathbf{s d}$ & $\mathbf{t}$ & $\mathbf{p}$ & $\mathbf{\eta 2}$ \\
\hline Fen Eğitimi & 88 & 103.19 & 12.36 & 119.546 & 1.827 & .070 & .327 \\
\hline Çevre Eğitimi & 48 & 99.73 & 9.44 & & & & \\
\hline *p<.05 & & & & & &
\end{tabular}

Tablo 7’ye göre "Fen Eğitimi” veya "Çevre Eğitimi” dersi alan öğretmen adaylarının sürdürülebilir çevre eğitimine yönelik davranış puanlarının istatistiksel olarak anlamlı bir şekilde farklılık göstermediği bulunmuştur [t(119,546)=1,827, p=.070, $\left.\eta_{2}=.327\right]$. Bu doğrultuda "Fen Eğitimi" dersini alan öğretmen adaylarının sürdürülebilir çevre eğitimine yönelik puanlarının ortalaması $(\bar{x}=103,19)$, Çevre Eğitimi dersini alan öğretmen adaylarının puanlarının ortalamasına $(\bar{x}=99,73)$ göre anlamlı bir şekilde farklılaşmamaktadır. Test sonucu hesaplanan etki büyüklüğü değeri $\left(\eta^{2}=0,327\right)$ öğretmen adaylarının sürdürülebilir eğitim puanlarının alınan ders türü üzerinde yüksek düzey etkiye sahip olduğunu veya başka bir ifade ile ortalamalar arasındaki söz konusu farkın etki büyüklüğünün "geniş” olduğunu göstermiştir (Cohen, Manion ve Morrison, 2007; Green ve Salkind, 2008; Field, 2009). Araştırma grubunda yer alan üniversitelerin ilgili ders bilgi kataloglarından edinilen bilgilere göre okul öncesi eğitimi lisans programlarında fen eğitimi 
dersinin zorunlu bir ders olduğu görülmektedir. Araştırmanın bu bulgusuna göre, özellikle fen eğitimi dersi kapsamında çevre ile ilgili konulara değinilmediği ya da ders içeriklerinin teorik bilgi düzeyinde kalarak yeterince uygulamaya yönelik olmadığını ve derslerin adaylarda tutum değişikliği oluşturmadığını düşündürmektedir. Benzer bir bulguya Timur, Yılmaz ve Timur (2013) tarafından yapılan çalışmada da ulaşılmış; araştırmacılar ilköğretim bölümü öğretmen adaylarının çevreye yönelik tutumlarının çevre ile ilgili ders alıp almamalarına göre değişiklik göstermediği sonucuna ulaşmışlardır. Gürbüz, Kışoğlu ve Erkol (2007) tarafından yapılan çalışmada da biyoloji bölümü son sınıf öğrencilerinin büyük bir çoğunluğu çevre derslerini yeterli bulmadığını ve derslerde adayların aktif olacağı ve çevreye karşı olumlu tutum ve davranış geliştirmelerini sağlayacak öğretim yöntemlerine yer verilmediğini belirtmişlerdir.

Öğretmen Adaylarının Sürdürülebilir Çevreye İlişkin Davranış Düzey Puanları İle Çevreyle İlgili Bir Sivil Toplum Kuruluşuna Üye Olma Durumuna İlişkin Bulgular

Öğretmen adaylarının sürdürülebilir çevreye ilişkin davranış düzeyleri ile çevreyle ilgili bir sivil toplum kuruluşuna üye olma durumu arasında bağımlılık ilişkisi olup olmadığını belirlemek amacıyla ki-kare testi uygulanmıştır.

Tablo 8. Sürdürülebilir Çevreye İlişkin Davranış Düzey Puanlarının Çevreyle İlgili Bir Sivil Toplum Kuruluşuna Üye Olma Durumuna Göre T-Testi Sonuçları

\begin{tabular}{|c|c|c|c|c|c|}
\hline & & & \multicolumn{3}{|c|}{ Sivil Toplum Kuruluşu Üyeliği } \\
\hline & & & Var & Yok & Toplam \\
\hline \multirow{8}{*}{ Düzey } & \multirow{2}{*}{ Düşük } & Gözlenen & 0 & 9 & 9 \\
\hline & & Beklenen & 0.9 & 8.1 & 9 \\
\hline & \multirow{2}{*}{ Orta } & Gözlenen & 31 & 207 & 238 \\
\hline & & Beklenen & 23.9 & 214.1 & 238 \\
\hline & \multirow{2}{*}{ Yüksek } & Gözlenen & 24 & 234 & 257 \\
\hline & & Beklenen & 25.9 & 232.1 & 257 \\
\hline & \multirow{2}{*}{ Çok Yüksek } & Gözlenen & 1 & 51 & 52 \\
\hline & & Beklenen & 5.2 & 46.8 & 52 \\
\hline \multirow{2}{*}{ Toplam } & & Gözlenen & 56 & 501 & 556 \\
\hline & & Beklenen & 56.0 & 501 & 6 \\
\hline
\end{tabular}

$\chi^{2}=7.292$

Tablo 8 incelendiğinde öğretmen adaylarının çevreyle ilgili bir sivil toplum kuruluşuna üye olup olmama durumu ile sürdürülebilir çevre eğitimine yönelik davranış puanları arasında istatistiksel olarak anlamlı bir ilişki bulunmamıştır. Başka bir ifadeyle öğretmen adaylarının çevreyle ilgili bir sivil toplum kuruluşuna üye olma durumları ile sürdürülebilir çevre eğitime yönelik davranış ölçeğinden elde ettikleri puanlara göre hesaplanan düzeylerin beklenen ve gözlenen değerleri arasındaki farkın anlamlı olmadığı sonucuna 
ulaşılmıştır. Araştırmada pek çok öğretmen adayının çevreyle ilgili bir sivil toplum kuruluşuna üye olmadıkları görülmektedir. Özmen, Çakmakçı Çetinkaya ve Nehir (2005) tarafından üniversite öğrencilerinin çevre sorunlarına yönelik tutumlarını etkileyen etmenlerin araştırıldığı çalışmada da öğrencilerin \%96,8'inin; Ek, K1lıç, Öğdüm, Düzgün ve Şeker'in (2009) üniversite öğrencileriyle yaptıkları çalışmada ise öğrencilerin \%86,5'inin bir çevre kuruluşuna üye olmadığı tespit edilmiştir. Araştırmanın bu bulgusuna göre çevreyle ilgili bir sivil toplum kuruluşuna üye olan adayların, üye oldukları sivil toplum kuruluşu tarafindan yürütülen çalışmalarda aktif olarak yer almadıkları, üyelik durumlarının kendilerinde sürdürülebilir çevreye ilişkin farkındalık ve çevre bilinci oluşturmadığı düşünülebilir.

\section{Sonuç ve Öneriler}

Araştırmadan elde edilen sonuçlara göre, kadın okul öncesi öğretmeni adaylarının erkek adaylara göre sürdürülebilir çevreye ilişkin davranış puanlarının daha yüksek olduğu tespit edilmiştir. Ege Üniversitesi'nde öğrenim görmekte olan okul öncesi öğretmeni adaylarının sürdürülebilir çevreye ilişkin davranış puanlarının örneklemde yer alan diğer üniversitelerde öğrenim görmekte olan öğretmen adaylarının puanlarına göre manidar bir şekilde daha yüksek olduğu belirlenmiştir. Öğretmen adaylarının sürdürülebilir çevreye ilişkin davranış puanlarının devam ettikleri sınıf düzeyine ve sürdürülebilir çevre eğitimini aldıkları ders türüne göre farklılaşmadığı görülmüştür. Ayrıca, öğretmen adaylarının çevreyle ilgili bir sivil toplum kuruluşuna üye olma ya da olmama durumlarının sürdürülebilir çevreye ilişkin davranışlarını etkilemediği belirlenmiştir.

Araştırma sonucu elde edilen bulgulardan yola çıkılarak öğretmen adaylarının sürdürülebilir çevreye ilişkin davranışlarını olumlu yönde geliştirmek ve kalıcı hale getirmek amacıyla şu önerilerde bulunulabilir:

- Okul öncesi eğitimi lisans programlarında uygulamalı fen eğitimi ve çevre eğitimi derslerin zorunlu hale getirilmelidir. Bu sayede öğretmen adaylarının kendilerini daha yetkin hissederek, mesleki hayatlarında sürdürülebilir çevreye ilişkin etkili uygulamalara yer vermeleri sağlanabilir.

- Üniversitelerde çevreye ilişkin çalışmalar yürüten öğrenci toplulukları oluşturularak, her program ve her sınıf düzeyinden öğretmen adayının bu topluluklarda aktif görev almaları ve bu sayede sürdürülebilir çevreye yönelik olumlu tutum ve davranışlar geliştirmeleri sağlanabilir.

- Bu araştırma Türkiye'deki beş üniversitenin okul öncesi eğitimi lisans programlarına devam eden öğretmen adayları ile sınırlıdır. Öğretim elemanlarının sürdürülebilir çevreye ilişkin davranış düzeylerini belirlemek üzere geliştirilen, bu araştırma kapsamında ise uygun istatistiksel yöntemlerin kullanılması sonucunda öğretmen adaylarına uygulanabilir hale getirilen "Sürdürülebilir Çevre Eğitimine Yönelik Davranış Ölçeği” değişkenler çeşitlendirilerek, farklı programlara devam eden lisans öğrencilerine de uygulanabilir. Böylece programlar arası farklılıklar ölçeğin tamamı ve/veya alt boyutlarında karşılaştırmalı olarak ele alınabilir. 


\section{Kaynaklar}

Aydın, F. ve Ünaldı, Ü. E. (2013). Coğrafya öğretmen adaylarının sürdürülebilir çevreye yönelik tutumları. Kalem Eğitim ve Insan Bilimleri Dergisi, 3 (1), 11-42.

Ayyıldız, H., Cengiz, E. ve Ustasüleyman, T. (2006). Üretim ve pazarlama bölüm çalışanları arası davranışsal değişkenlerin firma performansı üzerine etkisine ilişkin yapısal bir model önerisi. Muğla Üniversitesi Sosyal Bilimler Enstitüsü Dergisi, 17 (17), 21-38.

Aksoy, B. ve Karatekin, K. (2011). Farklı programlardaki lisans öğrencilerinin çevreye yönelik duyuşsal eğilimleri. Türkiye Sosyal Araştırmalar Dergisi, 15 (3), 23-36.

Atasoy, E. ve Ertürk, H. (2008). İlköğretim öğrencilerinin çevresel tutum ve çevre bilgisi üzerine bir alan araştırması. Erzincan Eğitim Fakültesi Dergisi, 10 (1), 105-122.

Bener, Ö. ve Babaoğul, M. (2008). Sürdürülebilir tüketim davranışı ve çevre bilinci oluşturmada bir araç olarak tüketici eğitimi. Hacettepe Üniversitesi Sosyolojik Araştırmalar E-Dergisi, 1-10. http://www.sdergi.hacettepe.edu.tr/makaleler/surdurulebilirtuketimdavranisi.pdf $\quad$ adresinden $\quad 03$ Aralık 2016 tarihinde erişilmiştir.

Büyüköztürk, Ş., Kılıç, Çakmak, E., Akgün, Ö. E., Karadeniz, Ş. ve Demirel. F. (2011). Bilimsel araştırma yöntemleri (6. Baskı). Ankara: Pegem Akademi Yayınc1lık.

Cohen, L., Manion, L., \& Morrison, K. (2007). Research methods in education. (Sixth Edition). NewYork: Routledge.

Çabuk, B. ve Karacaoğlu, C. (2003). Üniversite öğrencilerinin çevre duyarlılıklarının incelenmesi, Ankara Üniversitesi Eğitim Bilimleri Fakültesi Dergisi, 36(1-2), 189-198.

Demirci Güler, M. P. ve Afacan, Ö. (2012). A study on developing a behaviour scale towards sustainable environmental education. Journal of Baltic Science Education, 11 (3), 224-235.

Eagles P. \& Demare, R. (1999). Factors influencing children' environmental attitudes. Journal of Environmental Education, 30 (4), 33-37.

Ek, H. N., Kılıç N., Öğdüm, P. Düzgün, G. ve Şeker, S. (2009). Adnan Menderes Üniversitesinin farklı akademik alanlarında öğrenim gören ilk ve son sınıf öğrencilerinin çevre sorunlarına yönelik tutumları ve duyarlılıkları. Kastamonu Eğitim Dergisi, 17 (1), 125-136.

Engin, H. (2010). Coğrafya eğitiminde sürdürülebilir kalkınma, sürdürülebilirlik eğitimi ve çevre eğitimi konularının kazandırılması. (Yayımlanmamış Yüksek Lisans Tezi). Marmara Üniversitesi, Eğitim Bilimler Enstitüsü, İstanbul.

Erol, G. H., ve Gezer, K. (2006). Sinıf öğretmenliği öğretmen adaylarına çevreye ve çevre sorunlarına yönelik tutumları, International Journal of Environmental and Science Education, 1 (1), 65 -77.

Erten, S. (2005). Okul öncesi öğretmen adaylarında çevre dostu davranışların araştırılması. Hacettepe Üniversitesi Ĕ̈itim Fakültesi Dergisi, 28, 91-100.

Field, A. P. (2009). Discovering statistics using SPSS: and sex and drugs and rock ' $n$ ' roll (third edition). London: Sage publications.

Green, S. B. \& Salkind, N. J. (2008). Using SPSS for windows and macintosh (Analyzingand Understanding Data-Fifth Edition). Pearson PrenticeHall. New Jersey.

Gülay, H. ve Önder, A. (2011). Sürdürülebilir gelişim için okulöncesi dönemde çevre eğitimi. Ankara: Nobel Yayın Dağıtım. 
Gürbüz, H. ve Çakmak, M. (2012). Biyoloji eğitimi bölümü öğrencilerinin çevreye yönelik tutumlarının incelenmesi. Dicle Üniversitesi Ziya Gökalp Ĕ̈itim Fakültesi 162 Dergisi, 19, 162-173.

Gürbüz, H.ve Kışoğlu, M. ve Erkol, M. (2007), Biyoloji öğretmen adaylarının çevreye yönelik tutumlarının informal ve formal eğitim ortamları açısından değerlendirilmesi. A.Ü. Bayburt Eğitim Fakültesi Dergisi, 2 (3), 74-84.

Jöreskog, K. G. \& Sörbom, D. (1993). Lisrel 8: Structural equation modeling with the simplis command language. Hillsdale, NJ: Lawrence Erlbaum Associates Publishers.

Karabulut, E. (2004). Sürdürülebilir kalkınma anlayışının işletmelerde uygulanması. Tühis İ̧̧ Hukuku ve İktisat Dergisi, 19, 1-2.

Karasar, N. (2005). Bilimsel araştırma yöntemi. (14.Baskı). Ankara: Nobel Yayın Dağıtım.

Kline, R. B. (2005). Principles and Practice of Structural Equation Modeling. New York: The Guilford Press.

Ölçme, Seçme ve Yerleştirme Merkezi, www.ösym.gov.tr, adresinden 22 Mayıs 2014 tarihinde erişilmiştir.

Önder, A. ve Özkan, B. (2013). Sürdürülebilir çocuk gelişimi: Okul öncesi etkinliklerle çevre eğitimi. Ankara: Anı Yayınc1lı.

Özdamar, K. (2011). Paket programlar ile istatistiksel veri analizi (8. Bask1). Eskişehir: Nisan Kitabevi, 1. Cilt.

Özmen, D., Çakmakçı Çetinkaya, A., ve Nehir, S. (2005). Üniversite öğrencilerinin çevre sorunlarına yönelik tutumları. TSK Koruyucu Hekimlik Bülteni, 4(6), 330-344.

Sadık, F. ve Çakan, H. (2010). Biyoloji bölümü öğrencilerinin çevre bilgisi ve çevre sorunlarına yönelik tutum düzeyleri. Çukurova Üniversitesi Sosyal Bilimler Enstitüsü Dergisi, 19, (1), 351-365.

Şimşek, Ö. F. (2007).Yapısal Eşitlik Modellemesine Giriş Temel İlkeler ve LISREL Uygulamaları. Ankara: Ekinoks Yayınları.

Tabachnick, B. G. \& Fidell, L. S. (2006). Using Multivariate Statistics (5. Bask1). MA, Allyn, Bacon, Inc.

Tanrıverdi, B. (2009). Sürdürülebilir çevre eğitimi açısından ilköğretim programlarının değerlendirilmesi. Ë̆itim ve Bilim, 34 (151), 89-103.

Tikka, P.M., Kuitunen, M.T. \& Tynys, S.M. (2000), Effects of educational background on students' attitudes, activity levels and knowledge concerning the environment, The Journal of Environmental Education, 31 (3) 12-19.

Timur, S.,Yılmaz, Ş. ve Timur, B. (2013). İlköğretim Öğretmen Adaylarının Çevreye Yönelik Tutumlarının Belirlenmesi ve Farklı Değişkenlere Göre İncelenmesi. Ahi Evran Üniversitesi Kırşehir Eğitim Fakültesi Dergisi, 14 (2), 191-203.

UNESCO (2005). United Nations decade of education for sustainable development (2005-2014).

Uysal, Ö. (2013). Sürdürülebilir büyüme kavramının çevre ve ekonomik boyutlarının ayrıştırılması. Uluslararası Alanya İşletme Fakültesi Dergisi, 5 (2), 11-18.

Uzun, N. ve Sağlam, N. (2005). Sosyo-ekonomik durumun çevre bilinci ve çevre akademik başarısı üzerindeki etkisi. Hacettepe Üniversitesi Eğitim Fakültesi Dergisi, 29, 194-202. 


\section{Extended Abstract}

\section{Introduction}

Environment is an area that affects individuals' development and covers all aspects of life. Pre-school period is closely associated with it. In the pre-school period, children start to become aware of their relations with other people and with the culture and environment they live in. They also begin to make sense of the relationship network they act in. In this period, children's deep interest in the environment must be supported by adults and educators. In this way, their positive behaviors, skills, attitudes, respect, and sense of responsibility towards environment can be raised as of the early ages. Parents, educators, and other individuals in the society are role models to children through their interactions with the environment and their environmental attitudes and behaviors in this period. In this sense, making effective use of pre-school period, in which children's natural curiosity and eagerness to learn are intense, is important for children to know the environment they live in, develop positive attitudes towards it, gain awareness regarding environmental problems, and have a consciousness to protect the environment. For a sustainable environment, individuals should be turned into consumers having a consciousness to protect the environment as of the pre-school period. It is reported that consumers with environmental consciousness are aware of their contributions against environmental pollution, use resources sensitively by considering future generations and entire humanity, and are capable of evaluating the existence of resources in the environment, their costs of use, and the effects of their use on the environment and themselves.

Being environment-friendly, contributing to sustainability, using the world by keeping it livable for next generations, and minding the environment are among the responsibilities of every individual. Educators are one of the actors that play an active role in conveying this sense of responsibility to next generations. Educators standing as models to children must have positive environmental attitudes and display behaviors in accordance with these attitudes so that children are environmentally-conscious and have awareness of sustainable environment as of the pre-school period. The elimination of environmental problems requires the change of individual behaviors, and the change of individual behaviors requires the change of attitudes, knowledge, and value judgments. Hence, determining the behaviors and attitudes of pre-service pre-school teachers, who are today's young generation and are being trained for the education of pre-school children, towards sustainable environment is significant to enhance the quality of general knowledge and vocational training offered to them and contribute to their personal development. Accordingly, the present study aims to reveal pre-service pre-school teachers' behavior levels towards sustainable environment.

\section{Method}

While this study is based on the quantitive paradigm in the context of data, cross sectional survey model was used in the study. Survey research is a method which is used to determine participants' opinions, attitudes, interest and concern towards a specific issue. 
The population of the study consists of pre-service teachers attending the undergraduate programs of preschool education at state universities in Turkey. The sample of the study was determined as appropriate (accessible) sample on the basis of the purposeful sampling techniques in order to save time and money. The sample of the study is composed of 1,049 pre-service teachers studying at the undergraduate programs of pre-school education at Ağrı İbrahim Çeçen University, Anadolu University, Ege University, Kastamonu University, and Muş Alparslan University in their first, second, third, or fourth years and were voluntary to participate in the study.

A personal questionnaire which was developed by the researchers has been applied to obtain the personal information of the participants which had 5 questions as following: gender of the teacher candidate, university which he or she currently attending, grade, if he or she studied a sustainable environment course and if he or she is a membership of an environmentalist non-profit organization. "The Behaviour Scale for Sustainable Environmental Education" was the main data collection tool which has been developed to determine instructors' levels of behavior towards sustainable environment. This is a five-point Likert-type scale composed of 29 items and three sub-dimensions titled "Behaving in an Energy-Saving Way", "Following Environmental Publications or Broadcasts and Reacting to People Who Damage the Environment", and "Using Environmentally-Friendly and Recyclable Products". The variance explained by the entire scale has been found to be $55.251 \%$. The variance explained by the 15 -item sub-dimension titled "Behaving in an Energy-Saving Way" is $24.336 \%$. The factor loadings of the items under this sub-dimension vary from 0.474 to 0.792 . Cronbach's alpha coefficient calculated for the sub-dimension is 0.919 . The variance explained by the 8-item sub-dimension titled "Following Environmental Publications or Broadcasts and Reacting to People Who Damage the Environment" is $19.263 \%$. The factor loadings of the items under this sub-dimension vary from 0.627 to 0.782 . Cronbach's alpha coefficient calculated for the sub-dimension is 0.898 . The variance explained by the 6-item sub-dimension titled "Using Environmentally-Friendly and Recyclable Products" is $11.651 \%$. The factor loadings of the items under this sub-dimension vary from 0.436 to 0.724. Cronbach's alpha coefficient calculated for the sub-dimension is 0.793. Cronbach's alpha coefficient of internal consistency calculated for the entire scale is 0.944 .

This scale was developed in order to define the behavioral level of lecturers towards sustainable environment. Before the scale was applied, opinions of pre-school education experts were asked. Considering experts' feedback, it has been determined that there is no need to make any changes in the scale and the scale was suitable for applying to the teacher candidates The data obtained from the 1049 teacher candidates in the sample group were divided into two according to the layered sampling method and the internal consistency reliability was calculated on the data obtained from 493 participants. Cronbach Alpha internal consistency coefficient is calculated as 0.89 by calculating the whole scale. 
"Kolmogorov-Smirnov" normality test towards candidates' average scores is applied to detect significant differences and distribution measures. As a result of the test, it was determined that the scores of the teacher candidates for the sustainable environment are normally distributed but the gender and the type of the course related to the sustainability are not normally distributed at the categorical levels. In this context, research data were analyzed using Mann-Whitney $\mathrm{U}$ test, One Way Anova test, Chi-square and test analysis for independent samples.

Findings, Discussion and Conclusion

According to results of the research, woman pre-school teacher candidates have higher score towards sustainable environmental behavior than man candidates. This finding is consistent with the results of various studies investigating the effect of gender on environmental consciousness. It is underlined that preschool teacher candidates from Ege University have obtained significantly more score on attitude towards sustainable environment than teacher candidates from other universities. Undergraduate pre-school education placement scores for the 2011-2014 period show that Ege University's baseline scores were found to be higher than other universities' base in the research sample. This result suggests that there is a linear relationship between academic achievement and behavioral level scores for the sustainable environment.

Also, it is seen that teacher candidates' score towards sustainable environment is not differentiated by the grade and the lecture type of sustainable environment they studied. In other words, pre-service teachers' scores of behavior towards sustainable environmental education do not vary by grade. This finding indicates that pre-service teachers' social lives and educational experiences at university are not influential on gaining awareness regarding sustainable environment. According to the information obtained from the related course information catalogues of the universities included in the research sample, the science education course is compulsory in undergraduate pre-school education departments. This finding suggests that environmental issues are not specifically focused on within the scope of the science education course, or course contents do not go beyond being theoretical information and lessons do not lead to a change in pre-service teachers' attitudes.

Additionally, there is no significant relation between membership status of teacher candidates in environmentalist non-profit organizations and their attitude towards environment. This finding hints that pre-service teachers who are members to an environmental non-governmental organization do not gain enough consciousness concerning sustainable environment and are not adequately informed/guided about sustainable environment.

Based on the research findings, the following recommendations may be put forward to make a positive and permanent change in pre-service teachers' behaviors towards sustainable environment: 
- It can be suggested that hands-on science education and environmental education can be taught mandatorily. In this way, it may be possible for pre-service teachers to feel themselves more competent and give coverage to effective sustainable environment practices during their professional lives.

- Student communities that carry out studies on the environment in universities can be created so that each program and teacher at every grade level actively take part in these communities and develop positive attitudes and behaviors towards the sustainable community.

- This study is limited to pre-service teachers attending undergraduate pre-school education departments of five universities in Turkey. "The Behaviour Scale for Sustainable Environmental Education", which was originally developed to determine instructors' levels of behavior towards sustainable environment and adapted to pre-service teachers by use of appropriate statistical methods within the scope of the present study, may be administered to undergraduate students attending different departments through diversification of variables. In this way, differences between departments may be comparatively analyzed based on the entire scale and/or its sub-dimensions. 